\title{
A EXPERIÊNCIA DO SPORT EDUCATION NAS AULAS DE EDUCAÇÃO FÍSICA: UTILIZANDO $O$ MODELO DE ENSINO EM UMA UNIDADE DIDÁTICA DE FUTSAL
}

\author{
THE SPORT EDUCATION EXPERIENCE IN PHYSICAL EDUCATION CLASSES: \\ USING THE TEACHING MODEL IN A FUTSAL TEACHING UNIT
}

\section{LA EXPERIENCIA DEL SPORT EDUCATION EN LAS CLASES DE EDUCACIÓN FÍSICA: UTILIZANDO ESE MODELO DE ENSEÑANZA EN UNA UNIDAD DIDÁCTICA DE FÚTBOL SALA}

\author{
Tairone Girardon de Vargas*, Maríndia Mattos Morisso*, \\ Fernando Jaime González**, Rosalvo Luis Sawitzki ${ }^{*}$
}

Palavras chave: Educação Física Esportes. Metodologia. Ensino médio
Resumo: Esta pesquisa busca dialogar sobre as possibilidades educativas da utilização do modelo de ensino Sport Education nas aulas de Educação Física do ensino médio de uma escola pública. Para isso, desenvolvemos uma pesquisa-ação, um processo cíclico que resultou na integração do modelo em uma unidade didática de futsal. A partir da proposta, entendemos que a principal vantagem de se fazer uso do modelo de ensino é a melhora no processo de aprendizagem dos alunos. Para os professores, o Sport Education possibilita uma visualização geral do planejamento da unidade didática a ser trabalhada. No entanto, isso demanda um trabalho contínuo do docente, que, por vezes, precisa desenvolver atividades fora de sua carga horária semanal. Diante disso, entendemos que se faz necessário testar a experiência em diferentes ambientes para conhecer outras vantagens e dificuldades de se trabalhar com essa proposta.
Keywords:

Physical Education.

Sports.

Methodology.

Secondary

Education
Abstract: This research seeks to discuss the educational possibilities of the use of the Sport Education teaching model in Physical Education classes at a Secondary Education public school. For this, we conducted an action research study - a cyclical process that resulted in integration of the model into a futsal teaching unit. From the proposal, we understand that the main advantage of using the teaching model is the improvement in students' learning process. For teachers, Sport Education provides an overview of the teaching unit plan to be used. However, this demands permanent work from teachers, who sometimes need to develop activities outside of their weekly workload. Therefore, we understand that testing the experience in different environments is necessary to know other advantages and difficulties of working with that proposal.

Palabras clave: Educación Física. Deportes. Metodología. Educación Secundaria.
Resumen: Esta investigación busca dialogar sobre las posibilidades educativas de la utilización del modelo de enseñanza Sport Education en las clases de Educación Física de la enseñanza media de una escuela pública. Para ello, desarrollamos una investigaciónacción, un proceso cíclico que resultó en la integración del modelo en una unidad didáctica de futsal. A partir de la propuesta, entendemos que la principal ventaja de utilizar ese modelo de enseñanza es la mejoría del proceso de aprendizaje de los alumnos. Para los profesores, el Sport Education posibilita una visualización general de la planificación de la unidad didáctica a ser trabajada. Sin embargo, esto demanda un trabajo continuo del docente, que a veces necesita desarrollar actividades fuera de su carga horaria semanal. Frente a eso, entendemos que se hace necesario probar la experiencia en diferentes ambientes para conocer otras ventajas y dificultades de trabajar con esa propuesta.
*Universidade Federal de Santa Maria. Santa Maria, RS, Brasil.

E-mail: tairone_vargas@hotmail.com; marindiamorisso@gmail.com; rosalvols@hotmail.com

${ }^{*}$ Universidade Regional do Noroeste do Estado do Rio Grande do Sul. ljuí, RS, Brasil.

E-mail: fjg@unijui.edu.br

Recebido em: 15-01-2018 Aprovado em: 30-05-2018

DOI: https://doi.org/10.22456/1982-8918.79628 (c) (1) (8) Licence 


\section{INTRODUÇÃO}

O esporte é uma das principais práticas corporais tematizadas na Educação Física Escolar. No entanto, as aulas que tratam desse tema muitas vezes não têm um caráter educativo, assumindo, assim, dois formatos típicos. O primeiro pode ser caracterizado como uma reprodução formal da instituição esportiva, pautada no espírito da competividade e elitização dos melhores praticantes, enquanto que o segundo ocorre em ambientes desprovidos de qualquer intervenção pedagógica e pode ser definido como "não aulas", quando, normalmente, os alunos participam de jogos auto-organizados (GONZÁLEZ; FENSTERSEIFER, 2014), fato também conhecido como "rola bola" (MACHADO et al., 2010). Esses dois formatos refletem um período histórico da Educação Física, ocorrido antes e depois do movimento renovador dos anos 1980, respectivamente, marcas que até os dias atuais influenciam a prática pedagógica dessa disciplina.

Antes do movimento renovador, a Educação Física foi subordinada ao esporte. Segundo González e Fensterseifer (2009, p. 10), a "[...] EF estabeleceu uma relação simbiôntica com o esporte, por meio da qual esse fenômeno, em sua forma institucionalizada, acabou sendo praticamente hegemônico nas aulas [...]". Esse fato ocorreu de tal modo que a Educação Física assumiu a função da instituição esportiva dentro do ambiente escolar, desenvolvendo "[... não o esporte da escola, e sim o esporte na escola" (BRACHT, 1997, p. 22).

Nos tempos atuais, o lugar do esporte na Educação Física Escolar não é muito diferente, mesmo existindo alguns trabalhos que apontam outro sentido para essa tradição (CARLAN et al., 2012). Parece que criticar - como ocorre e/ou ocorreu - a tematização do esporte não foi suficiente para propiciar o surgimento de novas formas de trabalhos que superam tal situação. Para isso, é necessário pensar alternativas que amenizem as dificuldades do processo de ensino-aprendizagem do esporte dentro do ambiente escolar. De forma específica, é importante proporcionar mudanças em relação à metodologia de ensino utilizada para esse fim, analisando a aprendizagem dos alunos sobre o tema esporte, que é pertinente às aulas de Educação Física.

Nessa perspectiva de mudança, estudos nacionais e internacionais descrevem o modelo do Sport Education como uma alternativa para essa situação (SIEDENTOP, 1994; GRAÇA; MESQUITA, 2007; CALDERÓN LUQUIN; HASTIE; OJEDA PÉREZ, 2011; CALDERÓN et al., 2013; GINCIENE; MATTHIESEN, 2017). De acordo com Graça e Mesquita (2007, p. 410), esse modelo surge como uma "Aposta na democratização e humanização do desporto, de forma a evitar os problemas associados a uma cultura desportiva enviesada, tais como o elitismo, a iniquidade e a trapaça". O Sport Education é apontado como uma possibilidade para superar a visão reducionista da instituição esportiva nas aulas de Educação Física, e, assim, oportunizar aos alunos uma compreensão sobre e não uma vivência exclusivamente prática do esporte.

Dessa forma, entendemos ser pertinente testar as possibilidades educativas do Sport Education, considerando que o modelo de ensino ainda foi pouco explorado no contexto brasileiro. 0 trabalho, inicialmente, consistiu em um processo de (re)formulação da Educação Física na última etapa da educação básica. Dentro desse contexto de mudança utilizamos o Sport Education com a finalidade de contribuir para o desenvolvimento de uma unidade didática de futsal em turmas de $1^{\circ}$ ano. Apresentaremos a seguir as características do modelo de ensino e a forma como o trabalho foi realizado. Por fim, descreveremos o planejamento da unidade didática, discutindo as vantagens e as dificuldades de professores e alunos no desenrolar das atividades. 


\section{BASES TEÓRICAS}

Em meados dos anos 1990, o americano Siedentop propôs um modelo de ensino que mantém princípios autênticos do esporte e potencializa a sua ressignificação conforme as instituições escolares. Segundo Graça e Mesquita (2007), o Sport Education tem como objetivo reestruturar o ensino do esporte nas aulas de Educação Física, proporcionando elementos como a "[...] competência desportiva, o da literacia desportiva e o do entusiasmo pelo desporto, sendo o seu propósito formar a pessoa desportivamente competente, desportivamente culta e desportivamente entusiasta" (p. 410). Nesse sentido, essa reestruturação proporciona ao aluno uma vivência corporal autêntica do esporte, refletida de conhecimento para além da reprodução formal.

De acordo com Calderón Luquin, Hastie e Ojeda Perez (2011), o modelo de ensino pode ser considerado como a metodologia do novo milênio. Esses autores desenvolveram um estudo que apresentou as principais atualizações do Sport Education. A investigação concluiu que o modelo em questão pode contribuir com o nível de implicação e autonomia dos jovens estudantes, oportunizando a eles um prazer pela prática da atividade física.

Para que ocorra essa vivência autêntica da prática esportiva, o Sport Education utiliza seis características do esporte institucionalizado: a época esportiva, a filiação, a competição formal, o registro estatístico, a festividade e o evento culminante (SIEDENTOP, 1994). Essas características possibilitam ao aluno fazer parte de um ambiente de aprendizagem desempenhando importantes papéis, não somente de praticante, contemplando conhecimentos para além da reprodução exclusivamente prática do esporte.

A primeira característica é a época esportiva, conhecida como a unidade didática desenvolvida pelo professor. Na utilização desse modelo, a unidade deve atender a alguns requisitos, como um período prolongado de aulas, por exemplo. Essa condição proporciona aos alunos desenvolverem um conjunto de saberes corporais e conceituais sobre os conteúdos trabalhados. $O$ número de aulas deve ser considerado a partir dos objetivos da temática estudada; de maneira pontual, a quantidade de encontros deve proporcionar um conhecimento profícuo, ou seja, que a partir dessa intervenção os discentes possam se apropriar da prática fora do ambiente escolar. Além do mais, esse planejamento deve oportunizar a realização de uma sistematização corporal dos conhecimentos trabalhados no decorrer da época esportiva.

A segunda característica do Sport Education é a filiação, que consiste em oportunizar aos alunos participantes do processo um reconhecimento de sua importância na realização das aulas. Assim, todos, de uma maneira ou de outra, contribuem para o desenvolvimento dos saberes da disciplina. Em palavras mais pontuais, essa característica se refere à organização de equipes, que potencializam funções especificadas para cada membro e trabalham de maneira colaborativa no decorrer da época esportiva. Nesse espaço, cada qual, com o seu acervo de experiências, auxilia no compartilhamento de saberes em prol do melhor desenvolvimento de seu grupo.

Diante da filiação e estruturação de equipes, o modelo de educação esportiva sugere o desenvolvimento de uma terceira característica, definida como competição formal, ou seja, a realização de uma prática autêntica para os discentes participantes do processo. No entanto, essa organização deve superar alguns elementos do mundo institucionalizado e ser conduzida pelo docente a partir de um planejamento que oportunize situações equânimes de disputa 
e aprendizagem a todos os alunos. Cabe ressaltar que essa competição formal deve ser desenvolvida junto ao cronograma dos conteúdos trabalhados na unidade didática.

O desenvolvimento da competição interna na turma proporciona o aparecimento da quarta característica que faz parte do Sport Education, que é o registro estatístico. Esse movimento consiste no levantamento de informações sobre a competição e na sua divulgação. Através disso é possível pontuar os avanços obtidos pela turma, bem como ponderar o alcance das equipes e as singularidades de cada aluno. O meio de divulgação dessas informações pode ocorrer junto aos murais comuns da escola, redes sociais e também em meios de comunicação próximos utilizados pelos discentes, como a rádio da escola, por exemplo.

A quinta característica é a festividade, ou seja, um movimento de confraternização que deve ser estabelecido durante toda a unidade didática. Essa característica está presente em todas as outras, pois estabelece um ambiente agradável no desenvolvimento das tarefas demandadas pelo Sport Education. O clima festivo estimula o envolvimento dos alunos, fazendo com que se sintam parte do processo. Por fim, a sexta e última característica é o evento culminante. Pontualmente, é o fechamento da época esportiva (unidade didática), ou seja, a sistematização. No ensino dos esportes, esse encerramento pode ser desenvolvido por meio de um evento que oportunize uma competição entre as várias equipes das diferentes turmas da escola. $O$ fator determinante consiste em oportunizar aos alunos um protagonismo de seu trabalho e compartilhamento de seus conhecimentos.

A partir dessas características, podemos interpretar que o Sport Education pode ser uma estratégia metodológica condizente ao enfrentamento das dificuldades de se trabalhar o tema esporte na escola, ou então outras manifestações espetacularizadas pela sociedade. Esse modelo de ensino, ainda pouco explorado pelos professores brasileiros, proporciona aos alunos importantes contribuições para a aprendizagem. Graça e Mesquita (2007, p. 412) destacam que o referido modelo deve "(a) fornecer ao aluno tempo para jogar; (b) ensinar habilidades com transferibilidade para o jogo; (c) fornecer tempo para desenvolver jogadores competentes".

Nesse sentido, analisamos que o Sport Education supera as tradicionais práticas esportivas desenvolvidas nas aulas de Educação Física, proporcionando aos educandos possibilidades equânimes de aprendizagem. Graça e Mesquita (2007, p. 411) descrevem que "Nomeadamente os alunos menos dotados e as raparigas, habitualmente marginalizados nos programas tradicionais, sentem que, com os programas de educação desportiva, trabalham mais e dão um contributo importante para a equipe". Esses autores também destacam que por meio do Sport Education os alunos estabelecem um ambiente prazeroso e entusiástico. A vivência desse modelo de ensino oportuniza motivação para a turma, proporcionando maior envolvimento dos alunos com menor habilidade, que passam a ter oportunidade de desempenhar funções tão importantes quanto os demais na formação da sua equipe (GRAÇA; MESQUITA, 2007).

\section{PROCEDIMENTOS METODOLÓGICOS}

O trabalho consistiu no desenvolvimento de uma pesquisa-ação. Segundo Tripp (2005), esse tipo de pesquisa pode ser considerado uma estratégia para ser utilizada por professores e pesquisadores no desenvolvimento de estudos no meio educacional. De forma mais específica, 
Elliott (1978) destaca que a pesquisa-ação na educação consiste em interpretar e identificar problemas no contexto a ser estudado que podem ser resolvidos de forma colaborativa entre pesquisador e participante. Na Educação Física, Bracht et al. (2002), Betti (2013) e Rufino e Darido (2014) apresentam que a pesquisa-ação teve um maior crescimento a partir dos anos 1980, quando passou a ser utilizada para tratar de assuntos direcionados à área pedagógica e sociocultural. Nesse período, também se percebeu a necessidade de refletir sobre a prática docente que era desenvolvida, questionando as influências que a sustentavam.

A pesquisa-ação que realizamos ocorreu em uma escola pública, localizada em um município de pequeno porte do noroeste do estado do Rio Grande do Sul. A produção de dados teve início em 2013, quando ocorreu uma (re)formulação da Educação Física no ensino médio. Para isso, trabalhamos no formato de grupos de estudos com duas professoras colaboradoras. As docentes foram desafiadas a elencar os conteúdos que entendiam ser importantes para os seus alunos aprenderem na última etapa da educação básica. Na sequência, buscamos organizar as expectativas a partir de um saber para praticar, ou um saber vinculado ao praticar para conhecer. Segundo González e Fraga (2012), o saber praticar está relacionado a um conhecimento que proporciona ao educando uma proficiência de determinada prática. Já o praticar para conhecer vincula-se à vivência de uma manifestação da cultura corporal sem a apropriação que possibilite ao aluno praticá-la fora da escola.

A partir dessa ideia inicial, foram elencadas quatro práticas corporais para saber praticar e sete para praticar para conhecer. Na lógica do saber praticar foram escolhidos os seguintes subtemas: Esporte (modalidades: futsal e voleibol); Ginástica (exercício físico); Práticas Corporais Expressivas (danças gaúchas); e para praticar para conhecer foram definidos os subtemas: Práticas Corporais Junto à Natureza; Lutas; Esporte (modalidades esportivas: handebol, basquetebol, frisbee, bocha e atletismo). Os subtemas foram distribuídos nos três anos do ensino médio, conforme a Figura 1.

Figura 1 - Organização curricular da Educação Física no Ensino Médio

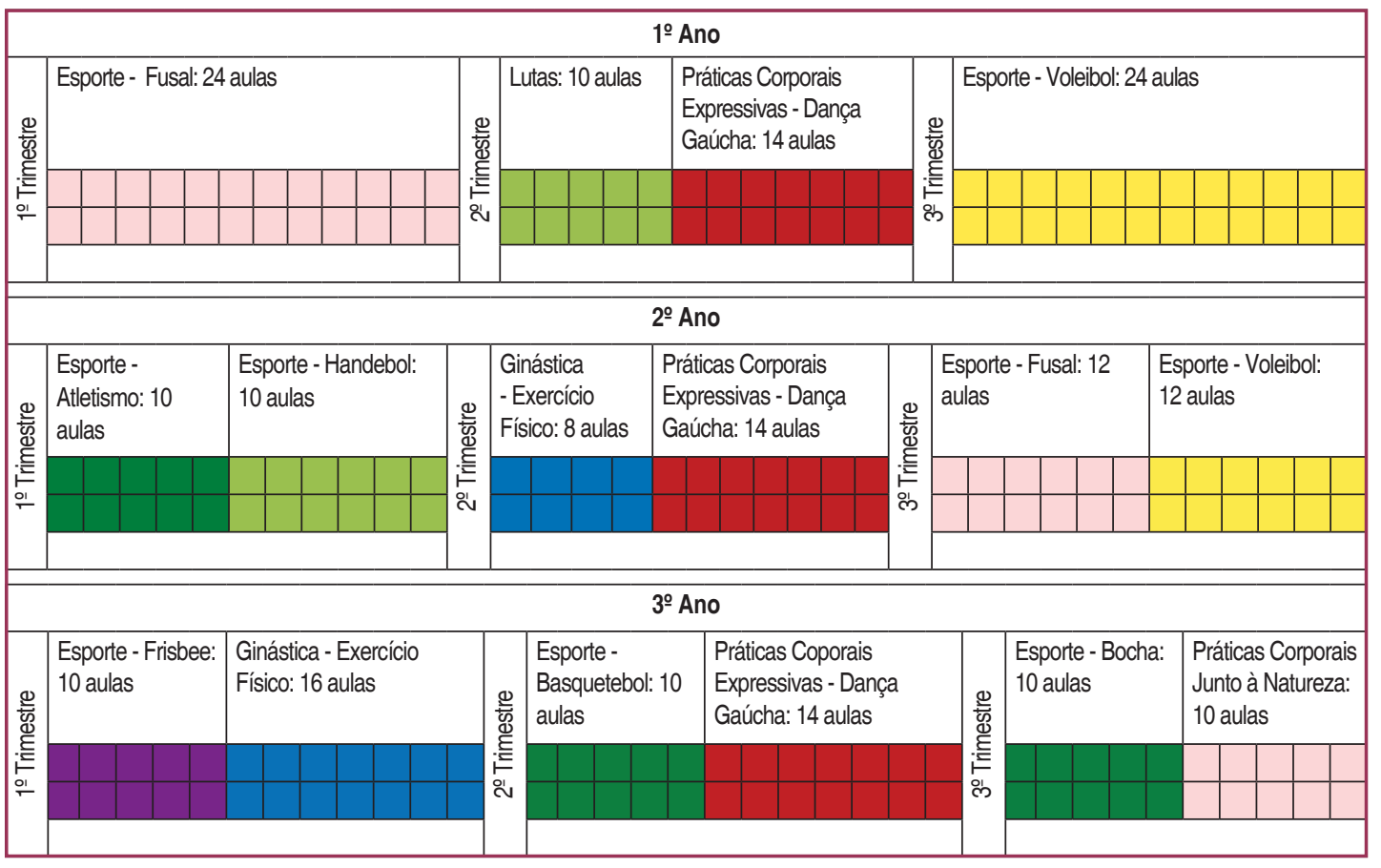

Fonte: Morisso, Vargas e González (2017). 
Diante da estruturação do novo plano de ensino da disciplina na escola, os grupos de estudos passaram a ter como ênfase o planejamento das unidades didáticas. A professora (a partir de 2014, somente uma docente seguiu trabalhando na escola), por diversas vezes, mostrou-se preocupada em planejar suas aulas conforme a organização. Nesse sentido, 0 uso de diferentes alternativas para o ensino e para (re)formular a Educação Física produziu unidades didáticas que podem servir como modelo para serem testadas em outros ambientes. Um exemplo disso são as aulas sobre a modalidade esportiva futsal, desenvolvidas a partir do Sport Education no $1^{\circ}$ ano do ensino médio e que apresentamos neste artigo.

A produção de dados sobre a experiência do Sport Education na unidade didática de futsal ocorreu no $1^{\circ}$ trimestre do ano letivo de 2014. Para isso realizamos quatro grupos de estudos de três horas cada um, antes de iniciar as aulas de Educação Física no ano letivo (no período de 19 a 25 de fevereiro de 2014), pois era importante que a maior parte do material estivesse pronta quando as aulas começassem. Os pesquisadores auxiliaram a professora na integração das características do Sport Education no planejamento enquanto a docente colaborou com tarefas sobre o tema de estudo (a Copa do Mundo) e atividades para a melhora do desempenho técnico-tático dos alunos. As discussões dos encontros foram relatadas em diários de campo.

As aulas da unidade didática de futsal no $1^{\circ}$ ano do ensino médio ocorreram durante todo $01^{\circ}$ trimestre do ano letivo de 2014 (entre os meses de março a junho). Em formato de observação participante acompanhamos todas as aulas de uma das turmas que trabalhou a unidade (24 horas/aula, mais o evento culminante). A observação participante, segundo Silverman (2009), é uma das técnicas utilizadas na pesquisa-ação que auxilia na melhor compreensão do contexto estudado. De forma prática isso consistiu em estar disponível para colaborar com solicitações da docente durante as aulas e participar de todas as etapas da organização do evento culminante. Os dados observados nesse momento da pesquisa também foram descritos em diários de campo.

Além dos encontros de estudo com a professora colaboradora e do acompanhamento das aulas da unidade didática, utilizamos na análise e discussão dos dados da pesquisa neste artigo relatos da professora e dos alunos resultantes de entrevistas semiestruturadas (VARGAS, 2015) e grupos focais (MORISSO, 2015), respectivamente. Esses instrumentos foram utilizados no final do ano letivo como forma de avaliar todo o processo de (re)formulação e entre as questões, ocorreram diálogos sobre a unidade didática de futsal e o modelo de ensino do Sport Education.

Também, achamos importante destacar que desde o movimento inicial da pesquisa em 2013 mantemos contato com a escola e com a professora. Temos como preocupação continuar o processo cíclico da pesquisa-ação; portanto, ainda ocorrem grupos de estudos a fim de revisar o planejamento das unidades didáticas, promovendo mudanças. Bolsistas de iniciação científica e mestrandos de universidades da região desenvolvem estudos, promovendo novas metodologias de ensino e a integração das tecnologias educacionais na prática pedagógica.

\section{ANÁLISE E DISCUSSÃO DOS DADOS}

Apresentamos a análise e discussão dos dados em três tópicos. No primeiro, descrevemos o planejamento elaborado de forma colaborativa entre a professora e os 
pesquisadores, dando ênfase para a integração das seis características do Sport Education na unidade didática. Em seguida, destacamos as vantagens proporcionadas pelo modelo no ensino do esporte. Por fim, discutimos sobre as desvantagens. As informações são apresentadas com base nos relatos dos diários de campo, escritos a partir das observações dos pesquisadores e dos dados produzidos em entrevistas com a professora e grupos focais com os alunos.

\subsection{O planejamento e as aulas de Educação Física utilizando o modelo Sport Education no ensino do Futsal}

O Sport Education é um modelo que apresenta contribuições importantes para o ensino do esporte nas aulas de Educação Física. Entretanto, suas características precisam fazer parte de um planejamento organizado que busque desconstruir a imagem do esporte elitizado, situação ainda considerada difícil para os professores. De acordo com Calderón Luquin, Hastie e Ojeda Perez (2011), a dificuldade do professor pode estar relacionada à interferência direta do fenômeno esportivo na vida social e também escolar do sujeito. Porém, os professores normalmente relatam que utilizar o modelo Sport Education proporciona um sentimento de renovação, e isso os motiva a melhorar a sua formação e, consequentemente, sua intervenção. Competitividade, elitização, superação de recordes e descoberta de talentos são algumas das características que, na escola, o esporte precisa trabalhar, compreender e superar.

A experiência em que utilizamos o Sport Education para o ensino do esporte nas aulas de Educação Física ocorreu dentro da (re)formulação da disciplina em uma escola pública de ensino médio, inserida em um contexto de pesquisa-ação. Diante de uma variedade de modalidades esportivas, optamos por utilizar o Sport Education na unidade didática de futsal para $01^{\circ}$ ano da última etapa da educação básica. Esse esporte estava programado para ser trabalhado 24 horas/aula no $1^{\circ}$ ano e 12 horas/aula no $2^{\circ}$ ano. Trata-se de uma modalidade muito praticada no município, e, por isso, ocorrem eventos e competições em que alguns alunos (nesse caso, somente os meninos) participam.

Dessa forma, entendemos que, devido a essas condições, desenvolver a modalidade no $1^{\circ}$ ano seguindo o modelo do Sport Education poderia proporcionar a todos oportunidades iguais de conhecer e praticar o esporte, além de incentivar um estudo crítico do futsal na comunidade. Nesse contexto, cabe destacar que nesta escola havia três turmas de $1^{\circ}$ ano $(111,112,113)$, e todas tiveram as aulas seguindo o mesmo cronograma.

O planejamento das aulas da unidade didática de futsal alicerçado no modelo do Sport Education procurou contemplar as dimensões conceituais, procedimentais e atitudinais. Além disso, as 24 horas/aula planejadas procuraram integrar as seis características, explicadas anteriormente. Essas características foram adequadas à realidade dos alunos e da escola para que o esporte fosse trabalhado envolvendo a participação de todos.

Transferindo as caraterísticas do modelo de ensino para a unidade em que ele foi desenvolvido, interpretamos que a época esportiva consistiu nas 24 horas/aula. O Quadro 1 mostra parte do plano de unidade, para exemplificar a organização da aula, realização de atividades e jogos. 
Quadro 1 - Fragmento da unidade didática de futsal

\begin{tabular}{|l|l|l|}
\hline Aulas & Conteúdos & Atividades \\
\hline Aula 5/6 & Organização e separação de equipes. & $\begin{array}{l}\text {-Possibilitar espaço para organização das equipes: } \\
\text { escolher nome, dividir os papéis e combinações para } \\
\text { fazer a bandeira, criar símbolos, uniforme, etc. }\end{array}$ \\
\hline Aula 7/8 & Atacante Com Posse de Bola (ACPB).. & $\begin{array}{l}\text {-Explicar os elementos técnicos táticos do ACPB. } \\
\text {-Atividade 01 e 02: Progredir e Finalizar. }\end{array}$ \\
\hline Aula 9/10 & Atacante Sem Posse de Bola (ASPB). & $\begin{array}{l}\text {-Explicar os elementos técnicos táticos do ASPB. } \\
\text {-Atividade 03 e 04: Movimentar-se para receber. } \\
\text {-1ํ Jogo: Equipe A X Equipe B - Equipe de Apoio: C. }\end{array}$ \\
\hline Aula 11/12 & $\begin{array}{l}\text { Defensor do Atacante Com Posse de } \\
\text { Bola (DACPB). }\end{array}$ & $\begin{array}{l}\text {-Explicar os elementos técnicos táticos do DACPB. } \\
- \text {-Atividade 05: Recuperar a posse de bola. } \\
-2^{\circ} \text { Jogo: Equipe C X Equipe A -Equipe de Apoio: B. }\end{array}$ \\
\hline
\end{tabular}

Fonte: Os autores.

A filiação aconteceu para integrar os alunos em equipes mistas (com meninos e meninas jogando juntos). Cada turma teve três equipes, e logo que foram formadas tiveram que escolher um nome, criar uma bandeira, definir cores que as representassem e fazer um uniforme ou algo que as identificasse. Além disso, nesse momento foram distribuídos diferentes papéis para que todos pudessem se envolver dentro de uma competição não só como jogadores, mas também como técnicos, capitães, secretários, árbitros, cronometristas e assessores de imprensa. Toda essa ligação com a equipe incentivou os alunos a estabelecer um compromisso com os companheiros, pois o envolvimento de cada um era fundamental para que os objetivos das aulas fossem alcançados.

A competição formal foi atração no final de cada aula, momento em que ocorria um jogo entre duas equipes da turma, enquanto a terceira realizava o apoio (conforme indicado no Quadro 1). A competição, organizada pelos alunos e pela professora, foi chamada de Campeonato Interno da Turma. As três equipes se enfrentaram em turno e em returno, e quem somou mais pontos no final da competição sagrou-se campeão. Para cada dia de jogo, as duas equipes que iriam se enfrentar precisavam estar munidas de suas bandeiras e vestidas com algo que as identificasse. Enquanto isso, a terceira equipe, que não iria jogar, era encarregada da arbitragem dos jogos, da cobertura jornalística e do levantamento de dados estatísticos. Esses registros realizados pelos alunos e posteriormente transferidos para um cartaz na sala de aula (Figura 2), murais da escola e rede social representam mais uma das características do Sport Education.

Figura 2 - Cartaz elaborado pelos alunos para o registro dos resultados dos jogos

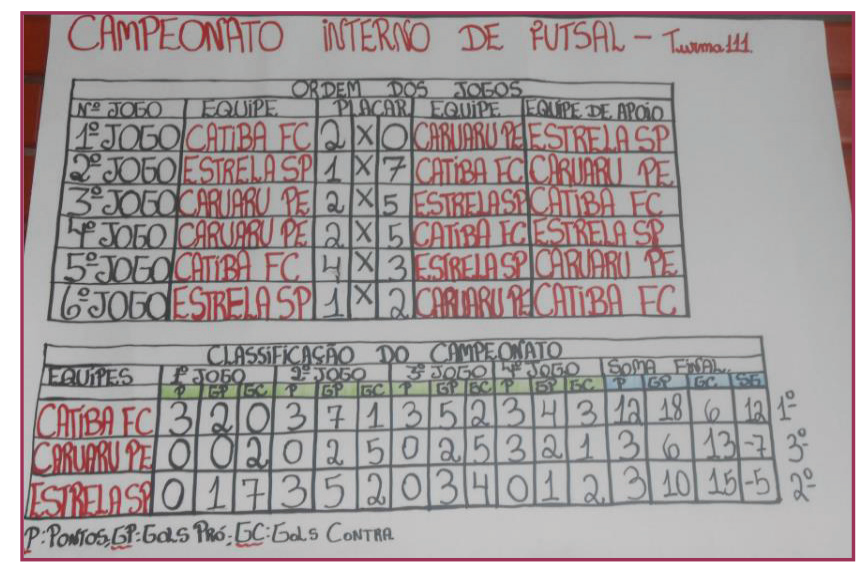

Fonte: Vargas, Morisso e González (2017). 
A festividade, outra característica do Sport Education, esteve presente durante a época esportiva, pois as aulas proporcionaram momentos de interação e confraternização entre os alunos por estarem sempre envolvidos com as tarefas em prol da sua equipe. No encerramento da unidade didática de futsal, ocorreu o evento culminante, com o objetivo de sistematizar os conteúdos estudados. Esse evento foi um dia de competição entre as três turmas de 1aㅡ. Todos foram premiados com medalhas pela participação e pelo envolvimento. Além disso, foi uma oportunidade para que os alunos do $1^{\circ}$ ano pudessem mostrar para a escola e os colegas de outras turmas o que tinham trabalhado durante a unidade. 0 evento ocorreu fora da escola, no ginásio municipal da cidade, um espaço diferente que proporcionou ainda mais grandiosidade à sistematização.

Além de desenvolver as seis características do Sport Education, conforme já descrito, a unidade didática também tratou de trabalhar elementos conceituais e atitudinais relacionados à prática da modalidade futsal. Os alunos foram incentivados a estudar as regras, as principais intenções táticas de cada subpapel (Atacante Com Posse de Bola - ACPB; Atacante Sem Posse de Bola - ASPB; Defensor do Atacante Com Posse de Bola - DACPB; Defensor do Atacante Sem Posse de Bola - DASPB) e a desenvolver trabalhos de pesquisa. Esses trabalhos foram elaborados pelos alunos dentro das próprias equipes. Os temas pesquisados foram: Esporte de Rendimento; Esporte de Participação; Esporte da Escola; Esporte na Escola; Futsal vs. Futebol; As diferenças de gênero na prática esportiva do futsal. Os alunos tiveram que apresentar os trabalhos para os colegas, discutir os assuntos e compartilhar de forma virtual o material pesquisado.

Diante do relato apresentado, podemos interpretar que utilizar o modelo de ensino Sport Education demanda um envolvimento diferente dos alunos e do professor nas aulas. Ambos precisam trabalhar dentro e fora da escola na realização das atividades. Para melhor compreender essas situações, discutiremos, a seguir, as vantagens e as dificuldades de se utilizar o modelo do Sport Education para o ensino do esporte nas aulas de Educação Física e, assim, auxiliar na reflexão sobre metodologias e modelos de ensino inovadores que podem contribuir com a valorização da área.

\subsection{As vantagens de se utilizar o modelo do Sport Education nas aulas de Educação Física}

As vantagens de se utilizar o modelo do Sport Education são muitas, tanto para os alunos como para os professores. De forma geral, os benefícios vão desde o envolvimento maior nas atividades até 0 aprendizado, que é consequência dessa participação mais ativa. Os estudos realizados sobre o uso do modelo nas aulas de Educação Física têm mostrado que ele se difere da reprodução de atividades técnicas descontextualizadas e isoladas, fato esse que se constitui a partir da oportunidade dos alunos utilizarem essas aprendizagens dentro das aulas e também fora delas (SIEDENTOP, 1994; GRAÇA; MESQUITA, 2007; CALDERÓN LUQUIN; HASTIE; OJEDA PÉREZ, 2011; CALDERÓN et al., 2013; GINCIENE; MATTHIESEN, 2017). Assim, o aluno passa a querer saber mais sobre o esporte, principalmente aquele que não se sentia valorizado na prática.

A experiência que acompanhamos com uso do Sport Education em uma unidade didática de futsal nos mostrou quatro vantagens do ensino do esporte nesse formato. A primeira foi o reconhecimento da importância do papel de cada aluno nas aulas. Durante a experiência 
buscou-se agrupar todos os alunos em equipes equilibradas e mistas (com meninas e meninos jogando juntos), e uma das regras era que pelo menos duas meninas deveriam jogar. A partir das informações analisadas nos diários de campo, interpretamos que todos ocuparam funções importantes, dentro e fora do jogo, quando realizavam o apoio, por exemplo, ou quando precisavam trabalhar para equipe. $O$ depoimento de um aluno reforça essa situação:

Eu acho que a primeira parte de ter futsal foi bom, porque eu particularmente não sabia jogar nada e eu aprendi bastante coisa, tanto teórica quanto prática. Foi algo que a gente teve desde a separação das equipes que a gente se envolveu fazendo bandeira, uniforme e teve medalha, isso eu achei legal (Aluno 2L - Grupo Focal).

Diante disso, entendemos que todos se sentiram valorizados em algum momento e capazes de contribuir com algo além de habilidades técnicas durante o jogo. Essa situação foi observada principalmente pelas meninas, que, dessa forma, conseguiram desempenhar funções importantes, iguais às dos meninos, jogando, fazendo arbitragem e registrando as aulas. No depoimento a seguir podemos identificar que a experiência do Sport Education proporcionou também maior envolvimento de todos:

Os outros anos davam a bola, se queria jogar jogava se não queria não precisava. E assim não, as gurias também conseguiram jogar, os guris passavam a bola. Não era jogar só para ganhar. $E$ todo mundo se envolveu, bem melhor assim (Aluno $1 \mathrm{~A}$ - Grupo Focal).

De certo modo, desempenhar diferentes funções condiz com a característica de filiação, e por isso a participação de cada aluno é fundamental para que o trabalho produza resultados positivos.

A segunda vantagem que podemos considerar sobre a utilização do modelo do Sport Education se refere ao trabalho colaborativo entre os alunos. Durante as aulas, observamos que as atividades que foram encaminhadas pela professora fizeram com que eles se envolvessem, trabalhassem juntos e, assim, cada um pôde contribuir com o que sabia fazer melhor: "A gente se envolveu em grupos, tivemos que fazer camiseta, manter a mesma equipe, fazer as tarefas" (Aluno 1A - Grupo Focal).

Mais uma vez podemos perceber a filiação como fator importante ligado à colaboração, que ocorre quando os alunos assumem um compromisso com sua equipe, pois se faltarem à aula, por exemplo, podem prejudicar os colegas no desenvolvimento das tarefas e do jogo. Portanto, novamente, a partir da análise dos diários de campo, interpretamos que, devido aos diferentes papéis que os alunos precisam desempenhar, o modelo de ensino proporciona maior envolvimento e colaboração entre os alunos.

A terceira vantagem em se utilizar o Sport Education para o ensino dos esportes é a possibilidade de oportunizar aos alunos a participação em um evento culminante. De forma específica, na experiência que apresentamos, os alunos, além de participarem da época esportiva durante as aulas da unidade didática, também puderam se envolver com um evento de sistematização em que todas as turmas de 1a ano participaram. Portanto, se durante as aulas os alunos enfrentaram os próprios colegas, no evento final puderam jogar com adversários das outras turmas. Para que o evento ocorresse, era necessário que todos se envolvessem e interagissem, e essa interação proporcionou aos alunos que nunca tiveram a oportunidade de fazer parte de um evento esportivo participar, independente do nível de suas habilidades (Diário de Campo 3 jun. 2014). 
Além disso, do ponto de vista do planejamento, podemos observar que a quarta vantagem é a definição de momentos que fazem parte da aula e ajudam a pensar o ensino do esporte diferente do modelo tradicional. No depoimento a seguir podemos observar uma avaliação da docente sobre o trabalho:

Daí a gente enxerga os resultados. Os resultados que acontecem dentro da turma, o envolvimento, 0 aprendizado deles, tu vês que eles crescem na unidade que tu trabalhas e que não é a mesma coisa. Hoje em um jogo que a turma faz tu já percebes é nítido, principalmente das gurias. É uma coisa rápida de ver o resultado (Entrevista 27 nov. 2014).

Todas essas vantagens apresentadas em relação ao envolvimento e à aprendizagem dos alunos mostram outros dois benefícios resultantes desse processo. 0 primeiro é a valorização da disciplina, pois a organização, a demanda de tarefas para os alunos e o estudo conceitual de temas relacionados à prática da modalidade remetem à ideia de que a disciplina tem conteúdo e necessita da mesma atenção que as demais. Já o segundo benefício é consequência do primeiro, pois está relacionado à valorização da professora que ministra as aulas, isso porque a importância da disciplina reflete no reconhecimento do trabalho da docente e, por conseguinte, em sua satisfação pessoal.

Dessa forma, podemos interpretar que esse modelo de ensino supera as tradicionais práticas esportivas desenvolvidas nas aulas de Educação Física. O Sport Education proporciona aos educandos condições similares de aprendizagem. Além disso, o uso do modelo pode motivar os professores na busca pela superação de que a Educação Física é uma disciplina exclusivamente prática, desenvolvendo aulas com características inovadoras, para, então, encontrar uma satisfação com o trabalho que realizam.

\subsection{As dificuldades de se utilizar o modelo do Sport Education nas aulas de Educação Física}

Conforme relatado anteriormente, o planejamento, de forma geral, é um grande desafio para os professores de Educação Física devido ao fato de a área ser conhecida como uma disciplina sem conteúdo. Apesar de o Sport Education apresentar muitos benefícios em relação ao aprendizado dos alunos, o planejamento das aulas utilizando o modelo é a principal dificuldade que observamos na experiência realizada. A demanda de trabalho e a necessidade de estar sempre envolvida com as turmas modificou a rotina da professora durante o desenvolvimento da unidade didática de futsal.

O docente que faz uso do modelo do Sport Education precisa estar muito envolvido com tal proposta, caso contrário, o trabalho não produz resultados satisfatórios. Na experiência que realizamos, percebemos que, mesmo tendo programado toda a unidade antes de começar a trabalhar com ela, a professora, por diversas vezes, precisou repensar o planejamento, além de ter que organizar situações que se tornavam necessárias no decorrer do desenvolvimento das aulas, como a definição das equipes, por exemplo. $O$ fato de a unidade ser mais longa faz com que se tenha mais tarefas a serem realizadas pelos alunos, o que ocasiona mais tarefas para a docente; isso porque todos os trabalhos planejados para serem desenvolvidos, conforme descrito anteriormente, precisam passar por uma elaboração consistente e, depois de produzidos pelos alunos, necessitam ser avaliados pela docente, sendo isso tudo junto ao elevado número de alunos por turma. 
Dessa forma, observamos durante 0 desenvolvimento da experiência que a principal dificuldade demonstrada pela professora foi o fato de precisar dedicar mais tempo para trabalhar nesta unidade. A carga horária excessiva e a quantidade de turmas em que ministrava aulas, além das turmas de $1^{\circ}$ ano, dificultaram o envolvimento da docente. Muitas vezes, as retomadas com os alunos foram superficiais, ou somente simples reprodução do que estava escrito nos cadernos da professora, sem nenhum tipo de questionamento e reflexão com os alunos (Diário de Campo 21 maio. 2014).

Por outro lado, uma das dificuldades que percebemos por parte dos alunos foi que nem todos tiveram uma participação ativa nas aulas. Alguns grupos não se envolveram em todas as atividades que foram propostas e alunos faltaram aulas importantes, inclusive 0 evento culminante. Observando a situação, tínhamos a impressão de que isso ocorria porque, amiúde, os alunos não compreenderam os objetivos de inclusão que o Sport Education tinha para oferecer. Provavelmente, a frustração desses alunos está relacionada à forma como desenvolviam o esporte nas aulas de Educação Física, antes de chegar ao ensino médio. Entendemos que somente o tempo e o desenvolvimento de outras unidades didáticas podem superar essa imagem.

Portanto, podemos perceber que a forma como o Sport Education necessita do envolvimento dos alunos é o que promove o aprendizado do esporte. 0 grande número de atividades que os discentes precisam desenvolver para que as aulas aconteçam faz com que eles precisem se dedicar para buscar um conhecimento que é para benefício próprio. No entanto, esse processo pode ser demorado, já que a forma como trabalhavam o esporte anteriormente não necessitava de tanto envolvimento. Além disso, todo esse trabalho também interfere na rotina do professor, que vê o modelo como uma novidade e que passa a ter mais trabalho para desenvolver.

\section{CONCLUSÃO}

O modelo do Sport Education é uma das alternativas para que o ensino do esporte nas aulas de Educação Física supere sua visão tradicional. Ao longo dos anos, o tema esporte foi trabalhado sem uma organização e intervenção pedagógica que desse a ele condições de produzir conhecimento para os discentes, além de ter sido confundido como sinônimo de Educação Física. No entanto, diante da necessidade de a área tratar de diferentes temas que fazem parte da cultura corporal de movimento, passou-se a buscar novas metodologias. A experiência apresentada sobre o ensino do esporte utilizando o modelo do Sport Education mostra uma alternativa de se trabalhar esse tema de uma forma que seja condizente com os objetivos da Educação Física.

A partir da proposta, entendemos que a principal vantagem de utilizar o modelo de ensino é a aprendizagem dos alunos. Os discentes são instigados a se envolver no decorrer de toda a unidade, desempenhando papéis que vão além das habilidades técnicas do esporte. Porém, quando os alunos têm dificuldades em compreender o objetivo de ensino desse modelo os resultados ficam fragilizados, e, muitas vezes, interferem no envolvimento e desempenho de outros alunos.

Para os professores, o uso do Sport Education possibilita uma visualização como um todo do planejamento da unidade didática a ser trabalhada. Essa organização auxilia o 
professor na legitimidade do seu trabalho e da Educação Física para com a direção da escola, colegas docentes e alunos. No entanto, isso demanda um trabalho contínuo do professor, que, por vezes, necessita desenvolver atividades fora de sua carga horária semanal. Entre essas atividades, podemos destacar a elaboração de trabalhos de pesquisa, a correção de tarefas realizadas pelos alunos, organização do campeonato interno da turma e do evento culminante.

Diante da experiência relatada, entendemos que para encontrar resultados mais significativos se fazem necessárias novas pesquisas em diferentes ambientes. Testar novas alternativas pode possibilitar o levantamento de dados similares ou diferentes dos que apresentamos. Como no Brasil são raros os estudos sobre o tema, acreditamos que seja uma necessidade emergente estudar o modelo de ensino Sport Education sobre diferentes peculiaridades para conhecer outras vantagens e dificuldades de se trabalhar com essa proposta.

\section{REFERÊNCIAS}

BETTI, Mauro. Educação Física Escolar: ensino e pesquisa-ação. 2. ed. Ijuí: Ed. Unijuí, 2013. (Coleção educação física).

BRACHT, Valter. Educação física e aprendizagem social. 2. ed. Porto Alegre: Magister, 1997.

BRACHT, Valter et al. A prática pedagógica em Educação Física: a mudança a partir da pesquisaação. Revista Brasileira de Ciências do Esporte, Campinas, v. 23, n. 2, p. 9-29, jan. 2002.

CALDERÓN LUQUIN, Antonio; HASTIE, Peter; OJEDA PEREZ, Diego Martínez. El modelo de educación deportiva (Sport Education Model). Metodologia de enseñanza del nuevo milenio? Revista Española de Educación Física y Deportes, n. 395, p. 63-79, Oct./Dic. 2011.

CALDERÓN LUQUIN, Antonio et al.; El modelo de educación deportiva y la enseñanza de la danza: Una experiencia en bachillerato. Tándem Didáctica de la Educación Física, n. 41, p.93-98, jan. 2013.

CARLAN, Paulo et al. O esporte como conteúdo da Educação Física Escolar: estudo de caso de uma prática pedagógica "inovadora". Movimento, v. 18, n. 4, p. 55-75, out./dez. 2012.

ELLIOTT, John. What is Action-Research in Schools? Journal of Curriculum Studies, v.10, n. 4, p. 3357, 1978.

GINCIENE, Guy; MATTHIESEN, Sara Quenzer. Modelo do sport education no ensino do atletismo na escola. Movimento, v. 23, n. 2, p. 729-742, abr./jun. de 2017.

GONZÁLEZ, Fernando Jaime; FENSTERSEIFER, Paulo Evaldo. Entre o "não mais" e o "ainda não": pensando saídas do não-lugar da EF Escolar I. In: Cadernos de Formação RBCE, v. 1, p. 9-24, set. 2009.

GONZÁLEZ, Fernando Jaime; FENSTERSEIFER, Paulo Evaldo. Aula. In: GONZÁLEZ, Fernando Jaime; FENSTERSEIFER, Paulo Evaldo. (Org.). Dicionário Crítico de educação física. 3. ed. rev. e ampl. ljuí: Ed. Unijuí, 2014. p. 64-67. 
GONZÁLEZ, Fernando Jaime; FRAGA, Alex Branco. Afazeres da Educação Física na escola: planejar, ensinar, partilhar. Erechim: Edelbra, 2012.

GRAÇA, Amândio; MESQUITA, Isabel. A investigação sobre os modelos de ensino dos jogos desportivos. Revista Portuguesa de Ciências do Desporto, v.7, n. 3, p. 401-421, 2007.

MACHADO, Tiago da Silva et al. As práticas de desinvestimento pedagógico na Educação Física Escolar. Movimento, v. 16, n.2, p. 129-147, abr./jun. 2010.

MORISSO, Maríndia Mattos. A (re)formulação da Educação Física em uma escola pública de ensino médio: 0 olhar dos alunos. 2015. 93f. Trabalho de Conclusão de Curso (Licenciatura em Educação Física) - Universidade Regional do Noroeste do Estado do Rio Grande do Sul, ljuí, RS, 2015. Disponível em: <http://bibliodigital.unijui.edu.br:8080/xmlui/handle/123456789/2691> Acesso em: 15 ago. 2016.

MORISSO, Maríndia Mattos; VARGAS, Tairone Girardon de; GONZÁLEZ, Fernando Jaime. Contribuições da rede social Facebook nas aulas de Educação Física. In: DARIDO, Suraya Cristina (Org.). Educação Física no Ensino Médio: diagnóstico, princípios e prática. ljuí: Unijuí, 2017. p. 205-225.

RUFINO, Luiz Gustavo Bonatto; DARIDO, Suraya Cristina. Pesquisa-ação e Educação Física escolar: Analisando o estado da arte. Pensar a Prática, v. 17, n. 1, p. 242-251, jan./mar. 2014.

SIEDENTOP, Daryl. Sport Education: Quality PE through positive sport experiences. Champaign: Human Kinetics, 1994.

SILVERMAN, David. Interpretação de dados qualitativos: métodos para análise de entrevistas, textos e interações. Porto Alegre: Artmed, 2009.

TRIPP, David. Pesquisa-ação: uma introdução metodológica. Educação e Pesquisa, v. 31, n. 3 , p. 443-466, set./dez. 2005.

VARGAS, Tairone Girardon de; MORISSO, Maríndia Mattos.; GONZÁLEZ, Fernando Jaime. O ensino do esporte utilizando o modelo sport education: o relato de uma experiência. In: DARIDO, Suraya Cristina (Org.). Educação Física no Ensino Médio: diagnóstico, princípios e prática. ljuí: Unijuí, 2017. p. 205-225.

VARGAS, Tairone Girardon de. Entre 0 antes e o depois: o estudo de caso de uma professora de Educação Física envolvida em um processo de (re)formulação colaborativa da disciplina. 2015. 57f. Trabalho de Conclusão de Curso (Licenciatura em Educação Física) - Universidade Regional do Noroeste do Estado do Rio Grande do Sul, ljuí, RS, 2015. Disponível em: < http:// bibliodigital.unijui.edu.br:8080/xmlui/handle/123456789/2690> Acesso em 18 ago. 2015. 